\section{Five-year follow up on the single level corpectomy}

\author{
Frank Phillip Castro* \\ Palo Alto Spine, LLC, 12307 Old LaGrange Rd., Suite 105, Louisville, KY 40245, USA
}

\section{Introduction}

Single-level Anterior Cervical Decompression and Fusion (ACDF) was initially performed using Iliac Crest Bone Graft (ICBG) [1]. Fusion rates improved when a surgical technique change, the addition of anterior plate fixation, was incorporated decades later [2,3]. Single level ACDFs with a machined allograft and plate fixation technique eventually became the industry standard as it demonstrated equivalent fusion rates with fewer complications than single level ACDFs with ICBG. This surgical technique was extended for use in patients with contiguous disk herniations. Multilevel ACDFs performed with machined allografts or interbody spacers and a two-level plate offered shorter operative times, less blood loss, better restoration of lordosis, and less immediate pain [4]. Successful multi-level ACDFs were strongly influenced by the bone graft source [5], the smoking addiction [6], and the construct stability [7]. Placement of two additional fixation screws in the central vertebral body, another improvement in the surgical technique, increased the construct strength compared to constructs with screws only placed into the end vertebral bodies [8]. Using allografts for multilevel ACDFs was a device disadvantage as they often resulted in high nonunion rates $[9,10]$.

Patient and surgeon satisfaction can be maximized when the non-union, complication and additional surgery rates are minimized [11]. For contiguous cervical disk disease the Anterior Cervical Corpectomy and Fusion (ACCF) technique allows surgeons to use local autologous bone graft (a device advantage) along with optimizing visualization and expanding the decompression (two additional technique advantages). As described above, ACDF outcomes benefited more from improvements in devices than changes in surgical technique. The ACCF surgical technique has not changed for decades; the only changes have been in the implants used. The initial ACCF experience with fibular allografts had unacceptably high expulsion, fracture, non-union and revision rates [12-15]. Supplemental halo fixation was not as successful as the addition of posterior cervical fixation for reducing fibular allograft associated complications [14-16]. Polyetheretherketone (PEEK) spacers were introduced with the "benefit" of having

\author{
More Information \\ *Address for Correspondence: \\ Frank Phillip Castro, MD, Palo Alto Spine, LLC \\ 12307 Old LaGrange Rd., Suite 105, Louisville, \\ KY 40245, USA, Tel: (502) 245-5767; (502) 245- \\ 5768; Email: bozothetruth@netscape.net \\ Submitted: July 08, 2021 \\ Approved: July 26, 2021 \\ Published: July 27, 2021 \\ How to cite this article: Castro FP. Five-year \\ follow up on the single level corpectomy. \\ J Neurosci Neurol Disord. 2021; 5: 083-086. \\ DOI: 10.29328/journal.jnnd.1001055 \\ Copyright: @ 2021 Castro FP. This is an open \\ access article distributed under the Creative \\ Commons Attribution License, which permits \\ unrestricted use, distribution, and reproduction \\ in any medium, provided the original work is \\ properly cited. \\ Keywords: Cervical corpectomy; Cervical \\ corpectomy complications; History of cervical \\ corpectomy; benchmarks

\section{Check for updates} \\ Open Access
}

a modulus of elasticity ( $15 \mathrm{GPa}$ ) closer to bone than titanium (110 GPa) [17]. However, PEEK spacers behaved similar to fibular allografts demonstrating unacceptably high rates of expulsion, fracture, subsidence and non-union $[18,19]$. The off-label use of cylindrical titanium surgical mesh implants for ACCF procedures started in 1986 [20]. Cylindrical cages were typically 8-12 $\mathrm{mm}$ in diameter and positioned centrally. Subsidence through the softer area of bone centrally often resulted in kyphosis or revision surgery [21].

The Palo Alto C-VBR was the first FDA 510(k) approved non-expandable cervical vertebral body replacement device [22]. The larger trapezoidal footprint was designed to engage the stronger cortical bone peripherally, reducing the risk of subsidence. The trapezoidal footprint with spikes placed anteriorly created wedges in the axial and coronal planes, reducing the risk of retropulsion into the spinal cord. The large channel within the device maximizes the amount of autologous bone graft inside the device and in contact with the vertebral end-plates. Increases in device stability and graft volume increase the probability of fusion [22]. The purpose of this study is to provide an outcome benchmark against which other FDA approved ACCF devices may be compared.

\section{Methods}

The study group was composed of 38 female and 21 male 
patients. The average patient was 54 years of age (range: 34 - 73). The body mass index (BMI) averaged $32\left(\mathrm{~kg} / \mathrm{m}^{2}\right)$, indicative of obesity. On average, ACCF patients were taking 10 different daily medications with $49(83 \%)$ of the patients taking at least four different medications on a daily basis. Thirty-one patients (53\%) were smokers and 21 (36\%) were on anticoagulation therapy that required pre- and postoperation management. Two of the 59 patients were American Society of Anesthesiologists (ASA) class I, 14 class II, 15 class III and 28 class IV. Thus, this cohort with an ASA average of 3.2 was at high risk for peri-operative morbidity, post-operative morbidity and non-union.

Only patients who underwent a single level corpectomy stabilized with a Palo Alto C-VBR and anterior plate fixation were included in this study. Patients who opted for a multilevel ACDF were excluded. Patients who underwent a "skip" corpectomy or a hybrid single-level ACCF and an ACDF at an adjacent level were also excluded. ACCF cases were performed between February 2013 and January 2015 by one of two surgeons. Thirty-five patients were included in the initial Investigational Device Evaluation (IDE) study submitted to the FDA and subsequently published in 2017 [22]. That Institutional Review Board (IRB) approved cohort of 97 patients included multi-level corpectomies and hybrid procedures. The additional 24 single-level ACCF cases in this investigation were performed between February and December 2015. All patients had surgery at the same hospital. The average follow-up was 61 months (range 11 - 82 months). Five patients died from unrelated causes, three of these patients had radiographic documentation of a solid fusion prior to their death. One patient had additional surgery: plate removal (Table 1). Sixteen patients $(27 \%)$ had a primary diagnosis of stenosis with myelopathy. Thirty-seven patients (63\%) had a primary diagnosis of disk herniations with radiculopathy. Six patients $(10 \%)$ had a primary diagnosis of a disk herniation adjacent to a non-union.

Fusion was determined on lateral flexion/extension $\mathrm{X}$-rays. The IDE study required the 35 patients in the IDE to have a CT to determine fusion along with lateral flexion/ extension X-rays. For the 24 ACCF patients enrolled after the IDE study was completed, CT scans were only ordered for symptomatic patients requiring additional evaluation of fusion consolidation. All imaging studies were interpreted by an independent Board Certified Radiologist and confirmed by the Attending Physician. We acknowledge that the Cervical Spine Research Society has since established more stringent criteria for determining fusion.

\begin{tabular}{|c|c|c|}
\hline Age/Gender & Months follow-up & Exclusion reason \\
\hline 48 yo $M$ & 5 & Lost to follow up after plate removal \\
\hline 46 yo. $M$ & 3 & Died from a myocardial infarction \\
\hline 88 yо. $F$ & 45 & $\begin{array}{c}\text { Died from a stroke } 42 \text { months after } \\
\text { surgery }\end{array}$ \\
\hline 73 yо. $\mathrm{F}$ & 66 & Died from pulmonary disease \\
\hline 46 yo $\mathrm{F}$ & 76 & Died from metastatic breast cancer \\
\hline
\end{tabular}

Complications monitored included dysphagia, instrumentation migration, revision surgery, and nonunion. Anterior migration of the cervical plate or a change in the angulation of the fixation screws was used to identify subsidence. This retrospective review of the patient charts was also IRB approved in 2020.

The author acknowledges the following three biases. ACCF was recommended over the two-level ACDF technique due to the unacceptably high frequency of non-unions he experienced and others have reported [23]. Note that six of the 59 patients in the ACCF cohort were individuals with a single level ACDF non-union and an adjacent level disk herniation. Anterior cervical techniques were always recommended over posterior cervical fusion techniques. His experience and other's reports of increased complications pertaining to posterior cervical wound infections and persistent pain led to the anterior approach bias [24]. The author designed and developed the FDA approved device (the Palo Alto C-VBR).

\section{Results}

Fusion was documented in 57 of 59 (97\%) patients. Dysphagia resulted in three plate removals and one esophageal dilatation (7\%). Two patients required posterior procedures: one for a non-union and the other for progressive kyphosis (3\%). Asymptomatic cage subsidence was visualized in two patients (3\%). A single deltoid palsy resolved spontaneously (2\%). One patient developed adjacent level disease requiring an extension of the anterior construct with an interbody spacer placed at the effected level. One patient had persistent radicular pain due to a residual osteophyte. The plate and the offending osteophyte were removed at a second surgical procedure. In all, 8 patients (14\%) required an additional surgical procedure during the five-year follow-up period.

\section{Discussion}

Majd, et al. were the first to report a 97\% fusion rate in 34 patients at 32 months with the cage/plate technique in 1999 [20]. High ACCF fusion rates have also been reported by other investigators $[21,25]$. Castellvi, et al., reported that the ACCF technique overcame the negative effects of smoking, pending litigation and workers' compensation status [21]. Their 38 patient cohort had a $100 \%$ fusion rate at one year's followup. The current study provides further evidence that device design improvements can improve long-term outcomes. This cohort was twice as large as the previously cited studies with two to four years of additional follow-up. This cohort was also unhealthier. This cohort had higher percentages of obesity, medical complexity, smokers, and coagulopathies.

The $96 \%$ fusion rate was attributed to three device advantages: the use of autologous bone graft [5], the large surface area exposing autologous graft to host bone [22], and the construct stability [7,16,26-28]. Autologous bone graft optimizes the osteoinductive, osteoconductive and 
osteogenic potentials within the fusion mass. Of note, the volume of autologous bone graft and graft-to-endplate contact surface areas are always larger for non-expandable devices as compared to expandable devices of the same diameter. Local bone harvested from the partial corpectomy eliminated the possibility of prolonged iliac crest bone graft harvest site pain and its associated complications [29-31]. Whereas the determination of fusion and the resulting fusion rate may be debatable, the $8 \%$ reoperation rate after an average of 5 years of follow-up is not.

Dysphagia (7\%) and anterior plate related complications in the current series were comparable to previous ACCF reports [21,25,32-34]. Transient dysphagia is commonly due to the esophagus being intubated, especially with high cuff pressures. Prolonged and/or excessive retraction forces on the esophagus may also result in transient dysphagia. Device related dysphagia, a mechanical effect due to the presence of a plate or the scar tissue covering the plate, is usually the underlying problem with long-term dysphagia. Hence, plate removal often eliminates dysphagia of this etiology. We did not observe any erosions through the esophagus or pharynx in our series. All plates removed were covered with a layer of connective tissue which had to be dissected away to expose the plate and screws being removed.

The trapezoidal shape of the Palo Alto C-VBR, as opposed to small cylinders, was designed to contact the stronger endplate near the vertebral body's periphery and prevent subsidence while maximizing the graft-endplate contact surface area. For device stability reasons, many expandable devices sacrifice graft bone-endplate contact area for deviceendplate contact surface area. Both patients with radiographic subsidence in this study were asymptomatic, surgery was therefore not recommended. Despite pre-and post-operative anticoagulation management for $36 \%$ of our patients, no post-operative hematomas were observed. As mentioned previously, ACCF is a higher blood loss procedure than two level ACDF surgery. Should a post-operative hematoma occur after an ACCF, immediate evacuation is strongly recommended [22].

The benefit of having large cohorts of patients with longterm follow-up is that recurring complications often identify areas where device or surgical technique improvements can be made. Improvements in polyethylene manufacturing and sterilization protocols have greatly improved the long-term results of total knee replacement surgery. Expandable cages may provide an immediate surgical technique benefit but their long-term device benefits are unproven. Between June 2014 and April 2017 the FDA received 17 Medical Device Related (MDR) Reports, product code MPQ24, for the X-Core Mini (the first FDA approved expandable cage for cervical corpectomies). Ten of the 17 reports involved additional surgery for collapse of height, subsidence or end-cap dislocation. Pojskic et al [35] studied 86 ACCF patients for 30 months. Thirty-nine patients
(54\%) had circumferential fusions. Thirteen patients $(15 \%)$ experienced instrumentation failure with the X-Core Mini dislocation within the first three weeks of surgery. Eight patients (9\%) experienced adjacent level disease and the overall fusion rate was $86 \%$. When compared to the results previously referenced, the non-expandable device appears superior. The cohort receiving a non-expandable cage had significantly fewer complications and significantly fewer additional surgeries [22]. Thirty-four of the ACCF cases in the Pojskic study were single level corpectomies which used the $\mathrm{X}$-Core Mini. Six single level ACCF patients required additional surgery, four revisions and two for adjacent level fractures. Thus, when the X-Core Mini was used for single level ACCFs and patients were followed for only 30 months, the additional surgery rate was $18 \%$.

In sum, the history of surgical technique and device design improvements leading up to single-level ACCFs was reviewed. The results from a cohort of high risk patients who received the first FDA approved non-expandable cage indicated for ACCF were presented. Only $14 \%$ of the patients had additional surgery during the 61 months of average follow-up with four being dysphagia related. Only one patient required surgery for an adjacent level problem and only one patient had a symptomatic non-union which required additional surgery. Long-term device specific follow-up will facilitate device design improvement and provide a standard for new device comparisons.

\section{References}

1. Smith GW, Robinson SA. The treatment of certain cervical spine disorders by anterior removal of the intervertebral disc and interbody fusion. J Bone Joint Surg Am. 1958; 40: 607-624. PubMed: https://pubmed.ncbi.nlm.nih.gov/13539086/

2. Bohler J, Gaudernak T. Anterior plate stabilization for fracturedislocations of the lower cervical spine. J Trauma. 1980; 20: 203-205. PubMed: https://pubmed.ncbi.nlm.nih.gov/7359594/

3. Oliver JD, Goncalves S, Kerezoudis P, Alvi MA, Freedman BA, et al. Comparison of outcomes for anterior cervical discectomy and fusion with and without anterior plate fixation: A systematic review and metaanalysis. Spine. 2018; 43: E413-422.

PubMed: https://pubmed.ncbi.nIm.nih.gov/29016435/

4. Uribe JS, Sangala JR, Duckworth EA, Vale FL. Comparison between anterior cervical discectomy fusion and cervical corpectomy fusion using titanium cages for reconstruction: analysis of outcome and longterm follow-up. Eur Spine J. 2009; 18: 654-662.

PubMed: https://pubmed.ncbi.nlm.nih.gov/19214597/

5. Shriver MF, Lewis DJ, Kshettry VR, Rosenbaum BP, Benzel EC, et al. Pseudoarthrosis rates in anterior cervical discectomy and fusion: a meta-analysis. Spine J. 2015; 15: 2016-2017.

PubMed: https://pubmed.ncbi.nlm.nih.gov/25982430/

6. Hillibrand AS, Fye MA, Emery SE, Palumbo MA, Bohlman HH, et al. Impact of smoking on the outcome of anterior cervical arthrodesis with interbody or strut-grafting. J Bone Joint Surg Am. 2001; 83-A: 668-673. PubMed: https://pubmed.ncbi.nlm.nih.gov/11379735/

7. Wang JC, McDonough PW, Kanim LE, Endow KK, Delamarter RB. Increased fusion rates with cervical plating for three-level anterior cervical discectomy and fusion. Spine. 2001; 26: 643-646.

PubMed: https://pubmed.ncbi.nlm.nih.gov/11246376/ 
8. Yilmaz M, Yuksel KZ, Baek S, Newcomb AGUS, Dalbayrak S, et al. Biomechanics of cervical 'Skip' corpectomy versus standard multilevel corpectomy. Clin Spine Surg. 2017; 30: E152-E161.

PubMed: https://pubmed.ncbi.nlm.nih.gov/22801457/

9. Peppers TA, Bullard DE, Vanichkachorn JS, Stanley SK, Arnold PM et al., Prospective clinical and radiographic evaluation of an allogenic bone matrix containint stem cells (Trinity Evolution Viable Cellular Bone Matrix) in patients undergoing two-level anterior cervical discectomy and fusion. J Orthop Surg Res. 2017; 12: 67.

PubMed: https://pubmed.ncbi.nlm.nih.gov/28446192/

10. Wang M, Chou D, Chang CC, Hirpara A, Liu Y, et al. Anterior cervical discectomy and fusion performed using structural allograft or polyetheretherketone: pseudoarthrosis and revision surgery rates with minimum 2-year follow-up. J Neurosurg Spine. 2019; 1-8.

PubMed: https://pubmed.ncbi.nlm.nih.gov/31835252/

11. Hillibrand AS, Fye MA, Emery SE, Palumbo MA, Bohlman $\mathrm{HH}$. Increased rate of arthrodesis with strut grafting after multilevel anterior cervical decompression. Spine. 2002; 27: 146-151.

PubMed: https://pubmed.ncbi.nlm.nih.gov/11805659/

12. MacDonald RL, Fehlings MG, Tator $\mathrm{CH}$, Lozano A, Fleming JR, et al. Multilevel anterior cervical corpectomy and fibular allograft fusion for cervical myelopathy. J Neurosurg. 1997; 86: 990-997.

PubMed: https://pubmed.ncbi.nlm.nih.gov/9171178/

13. RiewKD, Sethi NS, Devney J, GoetteK, ChoiK. Complications of buttress plate stabilization of cervical corpectomy. Spine. 1999; 24: 2404-2410. PubMed: https://pubmed.ncbi.nlm.nih.gov/10586468/

14. Epstein NE. Reoperation rates for acute graft extrusion and pseudoarthrosis after one-level anterior corpectomy and fusion with and without plate instrumentation: etiology and corrective management. Surg Neurol. 2001; 56: 73-80.

PubMed: https://pubmed.ncbi.nlm.nih.gov/11580933/

15. Epstein NE. Anterior dynamic plates in complex cervical reconstructive surgeries. J Spinal Disord Tech. 2002; 15: 221-227.

PubMed: https://pubmed.ncbi.nlm.nih.gov/12131423/

16. Epstein NE. The value of anterior cervical plating in preventing vertebral fracture and graft extrusion after multilevel anterior cervical corpectomy with posterior wiring and fusion: indications, results, and complications. J Spinal Disord 2000; 13: 9-15.

PubMed: https://pubmed.ncbi.nlm.nih.gov/10710142/

17. Rho JY, Ashman RB, Turner $\mathrm{CH}$. Young's modulus of trabecular and cortical bone material: ultrasonic and microtensile measurements. J Biomech. 1993; 26: 111-119.

18. Koehler S, Rasian F, Stetter C, Rueckriegel SM, Ernestus RI, et al Autologous bone graft versus PEEK cage for vertebral replacement after 1- or 2-level anterior median corpectomy. J Neurosurg Spine Feb. 2016; 24: 309-314.

PubMed: https://pubmed.ncbi.nlm.nih.gov/26460751/

19. KonigSA, SpetzgerU.ExperiencewithamodularPEEKsystemforcervica vertebral body replacement. J Spinal Disord Tech. 2015; 28: E89-95. PubMed: https://pubmed.ncbi.nlm.nih.gov/25099975/

20. Majd ME, Vadha M, Holt RT. Anterior cervical reconstruction using titanium cages with anterior plating. Spine 1999; 24: 1604-1610. PubMed: https://pubmed.ncbi.nlm.nih.gov/10457582/

21. Castellvi $A E$, Castellvi $A$, Clabeaux $D H$. Corpectomy with titanium cage reconstruction in the cervical spine. J Clin Neuroscience Apr. 2012; 19: 517-521.

PubMed: https://pubmed.ncbi.nlm.nih.gov/22321362/

22. Castro FP Jr, Majd ME. Anterior cervical corpectomy and fusion with the C-VBR. Am Colle Spine Surg J. 2018; 1.

https://escholarship.org/uc/backbone
23. Woo JB, Son DW, Lee SH, Lee JS, Lee SW, et al. Risk factors of allogenous bone graft collapse in two-level anterior cervical discectomy and fusion. J Korean Neurosurg Soc. 2019; 62: 450-457.

PubMed: https://pubmed.ncbi.nlm.nih.gov/31290298/

24. Youssef JA, Heiner AD, Montgomery JR, Tender GC, Lorio MP, et al. Outcomes of posterior cervical fusion and decompression: a systemic review and metaanalysis. Spine J. 2019: 19: 1714-1729.

PubMed: https://pubmed.ncbi.nlm.nih.gov/31075361/

25. Thalgott JS, Xiongsheng C, Giuffre JM. Single stage anterior cervical reconstruction with titanium mesh cages, local bone graft, and anterior plating. Spine J. 2003; 3: 294-300.

PubMed: https://pubmed.ncbi.nlm.nih.gov/14589190/

26. Galler RM, Dogan S, Fifield MS, Bozkus H, Chamberlain RH, et al, Biomechanical comparison of instrumented and uninstrumented multilevel cervical discectomy versus corpectomy. Spine. 2007; 32: 1220-1226.

PubMed: https://pubmed.ncbi.nlm.nih.gov/17495779/

27. Acosta FL Jr, Aryan HE, Chou D, Ames CP. Long-term biomechanical stability and clinical improvement after extended multilevel corpectomy and circumferential reconstruction of the cervical spine using titanium mesh cages. J Spinal Disord Tech. 2008; 21: 165-174.

PubMed: https://pubmed.ncbi.nlm.nih.gov/18458585/

28. Isomi T, Panjabi MM, Wang JL, Vaccaro AR, Garfin SR, et al. Stabilizing potential of anterior cervical plates in multilevel corpectomies. Spine. 1999; 24: 2219-2223.

PubMed: https://pubmed.ncbi.nlm.nih.gov/10562987/

29. Goulet JA, Senunas LE, DeSilva GL, Greenfield ML. Autogenous iliac crest bone graft; complications and functional assessment. CORR. 1997; 339: 76-81.

PubMed: https://pubmed.ncbi.nlm.nih.gov/9186204/

30. Armaghani SJ, Even JL, Zern EK, Braly BA, Kang JD, et al. The evaluation of donor site pain after harvest of tricortical anterior iliac crest bone graft for spinal surgery: A prospective study. Spine. 2016; 41: E191-196.

PubMed: https://pubmed.ncbi.nlm.nih.gov/26571154/

31. Calori GM, Colombo M, Mazza EL, Mazzola S, Malagoli E, et al. Incidence of donor site morbidity following harvesting from iliac crest or RIA graft. Injury. 2014: 45: S116-120.

PubMed: https://pubmed.ncbi.nlm.nih.gov/25457330/

32. Derman PB, Lampe LP, Alexander P, Pan TJ, Kueper J, et al. Demographic, clinical and operative factors affecting long-term revision rates after cervical spine arthrodesis. J Bone Joint Surg Am. 2016; 98 : 1533-1540.

PubMed: https://pubmed.ncbi.nlm.nih.gov/27655980/

33. Hwang SL, Lee KS, Su YF, Kuo TH, Lieu AS, et al. Anterior corpectomy with iliac bone fusion or discectomy with interbody titanium cage fusion for multilevel cervical degenerative disc disease. J Spinal Disord Tech. 2007; 20: 565-570.

PubMed: https://pubmed.ncbi.nlm.nih.gov/18046168/

34. Lau D, Chou D, Mummaneni PV. Two-level corpectomy versus threelevel discectomy for cervical spondylotic myelopathy: a comparison of perioperative, radiographic and clinical outcomes. J Neurosurg Spine. 2015; 23: 280-289.

PubMed: https://pubmed.ncbi.nlm.nih.gov/26091438/

35. Pojskic M, SaB B, Nimsky C, Carl B. Application of expandable cage reconstruction of the cervical spine in a consecutive series of eightsix patients. Medicina. 2020; 56: 642.

PubMed: https://pubmed.ncbi.nlm.nih.gov/33255605/ 